\title{
Management of the Development of a Modern Teacher's Digital Competencies
}

\author{
Olga V. Alekseeva $\left.{ }^{1 *[O R C I D} 0000-0003-2564-2512\right]$, \\ Natalya V. Alexandrova 1[ORCID 0000-0001-9115-0378], \\ Tatyana P. Skvortsova 2[ORCID 0000-0002-9056-4461], \\ Elena M. Zorina 3[ORCID 0000-0002-9589-3678]
}

\author{
${ }^{1}$ Yaroslav-the-Wise Novgorod State University, Veliky Novgorod, Russia \\ ${ }^{2}$ Institute of Art Education and Cultural Studies of the Russian Academy of Education, Moscow, Russia \\ ${ }^{3}$ Saint Petersburg State University of Architecture and Civil Engineering, Saint Petersburg, Russia \\ roolalex@yandex.ru
}

\begin{abstract}
Motivation is the basis for managing the development of teachers' competencies in the modern education system. The motivational component in the study is considered as a set of internal and external motives of the teacher to use modern digital technologies, accompanied by the processes of forming an internal desire to achieve success and a sincere and personally significant desire to improve themselves in this area. The purpose of the study is to study the possibility of managing the development of teachers' digital competencies with different motivations. The article examines the features of teachers' motivation in mastering digital competence, revealed the nature of teachers' awareness of the possibilities of using information and communication tools in teaching schoolchildren, and identified the main problems that teachers with different motivations have that prevent the formation and deepening of their digital competencies. Features of motivation were studied using A.A. Rean's methodology "Motivation for success and fear of failure" and a questionnaire about teachers' ideas about the use of information and communications technologies in teaching their subject. About $30 \%$ of teachers from the experimental sample focus on achieving success in the development of digital competencies, although the proportion of teachers without a pronounced motivational orientation and focus on avoiding failure is approximately the same. This indicates an insufficiently effective methodological and psychological support for teachers who cannot independently cope with the urgent task of modern education - the formation of digital competence. This happens for various reasons - fear of mastering new technologies, age composition, inability to take advanced training courses, etc. Thus, the strategy and tactics of developing digital competencies of teachers who avoid failure and are motivated to achieve success have fundamental differences. Methodological and psychological-pedagogical support for specialists with low and high levels of motivation is built within the framework of an individual trajectory of their professional development and self-improvement. The results of the study can be used both in the design of higher education programs and programs for professional training and retraining of teaching staff.
\end{abstract}

Keywords: teacher's digital competencies, competency development management, motivational component of digital competency

\section{INTRODUCTION}

With the development of artificial intelligence (AI) technologies, digital environments, virtual (VR) and augmented reality (AR), online interaction education resources are expanding, conditions are being created for individual learning, dynamic assessments and facilitating interaction in interactive, mobile or blended learning.

Education is becoming available to many segments of the population, including people with disabilities. 
K. Zhang and A.B. Aslan [1] conducted an exhaustive review of empirical research on the application and implementation of digital technologies in education, conducted by scientists from different countries over the past 30 years. They concluded that it is essential to bridge the gap between technological innovations in the field of digital technologies and their educational potential in order to fully realize it. In our opinion, the solution to the problem of the discrepancy between the rapid development of digital technologies and traditional non-digital teaching methods lies in the development of digital competencies of a modern teacher.

Norwegian researchers L. Brevik, G. Guðmundsdóttir, A. Lund, and T. Strømme note that it is a difficult task to integrate professional digital competencies of students into school practice and university seminars, who will become teachers in the future [2]. Also, these authors identify the concepts of digital literacy and digital competencies, which is not consistent with our understanding of these phenomena. So, under digital literacy, we, together with D.A. Mezenttseva, E.S. Dzhavlakh, O.V. Eliseeva, A.S. Bagautdinova, understand the ability to perform various operations with information, that is, the ability to work with media content [3]. Such an understanding of the phenomenon of "digital literacy" is confirmed by a number of modern studies [4]. Digital competencies are a set of knowledge, skills and attitudes that allow the teacher to adequately and effectively use digital tools and related teaching methods and techniques to meet the educational needs of students and teachers. We can consider the concept of "digital literacy" and the experience of using modern digital tools as well as old ones by teachers, rather than integrating new technologies into a personal teaching model [5], as identical. Another difference between digital competence and digital literacy is the change in the presentation of digital learning material and in its processing [6].

Identification of the development of the prerequisites for digital competencies of teachers is described in some detail in the study by A.V. Ilyina, A.V. Koptelov, A.V. Mashukov, A.G. Oboscalov. The authors presented for implementation a roadmap for the development of this area for teachers of additional professional education [7]. However, in the presented roadmap there is no reference to personally significant factors in the development of digital competencies of teachers, such as personal involvement in the process of forming digital competencies, motivational and psychological readiness to master new teaching methods and technologies of working with students. It is impossible to deny the change in the worldview of modern man, which is associated with people's awareness of their new role not as isolated people, but as interconnected information agents. This selfimage is the result of social media immersion, ubiquitous access to knowledge, and widespread use of mobile devices. One of the elements of such selfassessment is personal online identity [8], which, in turn, plays an important role in the development of a modern teacher's digital competencies. A study of this problem in Germany showed that the basic digital skills of teachers and technology-related teaching skills are more important than the direct resources of digital technologies [9]. In our opinion, the fundamental thing in this process is the presence of positive motivation for teachers to master digital competencies, that is, orientation towards achieving success in this type of activity.

The motivational component of digital professional competence is a set of internal and external motives of a teacher to strive to apply modern digital technologies, accompanied by the processes of forming an internal desire to achieve success with a sincere and personally significant desire to improve themselves in the field of education [10]. For example, a study of the work motivation of teachers in Malaysia showed a direct impact of the unfavorable epidemiological situation on increasing the motivation of teachers to work remotely. At the same time, this study clarifies that the situation associated with the transition to online learning mode causes rather high anxiety among teachers [11], which, in our opinion, cannot favorably influence the formation of positive motivation to master digital competencies. The formation of a stable positive motivation for the development of digital competencies of a teacher includes a set of external (adoption of attitudes for the development of digital skills, meeting expectations) and internal (selfrealization, the joy of learning and creativity, involvement in relationships for the exchange of experience with other teachers) motives [12].

A separate problem is the ability to intuitively stay ahead of existing technologies, since it is necessary to train a professional of the future [13], and digital technologies develop and become more complex much faster. A modern teacher should not only have digital competencies, but also build training in such a way that a modern student would be successful in learning a profession and then become a sought-after specialist for many years. He must have the degree of flexibility and self-learning motivation that will allow him to remain in the labor 
market with constantly changing and becoming more complex technologies.

Competent management of the development of digital competencies of a modern teacher contributes to the achievement of this task.

Based on the analysis of current research, several research questions arise: How can one form the motivational readiness of modern teachers to master digital competencies? How to qualitatively and in accordance with the individual trajectory of professional development manage the process of formation of modern teachers' motivational readiness to master digital competencies? What methods and techniques can measure the quality of motivational readiness for the formation of digital competencies?

\section{MATERIALS AND METHODS}

The purpose of the study was to study the possibility of managing the digital competencies of teachers with different motivations.

The study hypothesized that the personal motives of teachers to master digital technologies and use digital educational resources and modern ICT in teaching schoolchildren are associated both with the level of general awareness of the possibilities of these educational tools and with the experience of using them in their own practice.

Research tasks:

- to study the features of the motivational component of teachers' digital competence;

- to identify the awareness of teachers about the possibilities of using information and communication tools in teaching schoolchildren;

- to identify the main difficulties that arise for teachers with different motivations, preventing the improvement of their digital competencies.

Research methods: testing, questioning, systematization and classification, comparative data analysis, correlation analysis.

\section{RESULTS}

The main idea of the study is that the management of teachers' digital competencies is created taking into account the peculiarities of motivation and their ideas about the possibilities of ICT tools. Therefore, in the course of the study, much attention was paid to the study of the motivational component of teachers' digital competence.

The formation of a motivation system for teaching staff based on a student-centered approach is one of the priority tasks for the digital transformation of education [14]. At the same time, the management of teachers' motivation is poorly taken into account in this process.

The conducted testing of school teachers allowed:

- to identify the type of motivation for the development and implementation of information and communication learning tools in the educational process,

- to determine the range of tasks that teachers are trying to solve by improving digital competencies.

The type of motivation was determined by the A.A. Rean's method "Motivation for success and fear of failure" [15]. The orientation of teachers to success when using ICT tools was revealed. The study involved 128 teachers of primary and secondary schools, implementing various school subjects.

The results obtained indicate that among the teachers, specialists focused on achieving success prevail $(36 \%)$. Of these, the motivation for success is pronounced in $19 \%$. Such teachers are confident in themselves, in their abilities, responsible, proactive and active. They are distinguished by perseverance in achieving the goal, purposefulness, and $17 \%$ of teachers are dominated by needs and hopes for success. However, a fairly high percentage of teachers tend to avoid failure (34\%). However, the motivation to avoid failures is clearly expressed only in $16 \%$ of the respondents. The remaining $18 \%$ tend to avoid failure to a greater extent, but can also focus on success in their professional activities. 30\% of teachers did not reveal a pronounced motivational pole.

In the course of further research, all groups of teachers took part in a survey, which made it possible to identify the tasks facing them, for which they are ready to develop digital competencies.

The questionnaire survey showed that teachers are aware of the variety of ICT tools. A number of Several questions in the questionnaire were aimed at identifying the experience of teachers in using these tools in the educational process. Other questions clarified the difficulties that differently motivated 
teachers face when using digital learning tools in the educational process.

Teachers who avoid failure use ICT tools mainly to interest students $(100 \%)$, to more successfully solve subject pedagogical tasks $(100 \%)$. The development of ICT tools is called by them an important step in professional self-improvement and basic professional skills (76\%), opens up the possibility of using new resources in professional activities $(76 \%)$.

For educators who are more focused on avoiding failure, it is also important that ICT tools, if used skillfully, will help to keep students interested $(70 \%)$. The motives for gaining new experience and professional self-improvement in this group of respondents are less pronounced $(61 \%)$.

Teachers, who are more focused on success, are dominated by the choice of solving subject tasks using ICT tools, as well as the interest in novelty. $86 \%$ of teachers from this group consider digital resources as a means to get students interested. Important for them is both the development of new digital resources and the acquisition of new experience.

The identified types of motivation were classified into five levels: high, above average, medium, below average, low. A high level of teachers' motivation to use ICT tools in the classroom was adopted as a type of motivation with pronounced motives for achieving success. The type of teachers' motivation avoiding failure corresponded to a low level.

Teachers whose motivation is related to achieving success more often chose answers about students' interest in using ICT tools (88\%). They are dominated by the motives of novelty $(83 \%)$, as well as professional self-improvement (88\%).

In the course of the study, a correlation analysis was carried out between the type of school teachers' motivation and their experience in using technical tools and digital products. The relationship between teachers' motivation of and general awareness of the possibilities of using ICT tools in teaching was also revealed. The analysis was carried out on the basis of determining the level of statistical significance of the correlation coefficient, determined by the Pearson formula.

The results of the correlation analysis showed a positive relationship between the type of teachers' motivation and the level of general awareness of the possibilities of using information and communication tools in the educational process $\mathrm{r}=0.25 \quad(\mathrm{~N}=128, \rho=0.01)$. A significant positive relationship was also found between the willingness to use various digital educational products in the process of teaching schoolchildren and the personal motivation of teachers $\mathrm{r}=0.25(\mathrm{~N}=128, \rho=0.01)$. The experience of using various technical learning tools has a positive relationship with a high type of teacher motivation $\mathrm{r}=0.18 \quad(\mathrm{~N}=128, \quad \rho=0.05)$. Teachers' awareness of hardware and software tools is closely related to teachers' experience in using a variety of software products $0.73(\mathrm{~N}=128, \rho=0.1)$.

Let us characterize the digital competence of teachers with a low level of motivation.

Teachers who avoid failure also use a computer, a multimedia projection system, and interactive whiteboards in their work. During the survey, teachers note that they have experience with both presentation preparation programs and text editors, spreadsheets. Teachers find it difficult to name specific digital educational products. Among the advantages of using digital products, $29 \%$ of teachers in this group include the ability to illustrate in teaching phenomena and objects that are inaccessible in the lives of schoolchildren. Teachers of this group find it difficult to identify and characterize the disadvantages of using ICT tools in education process. Among the problems of digitalization of education, the most popular answers are ignorance of digital educational content and insufficient provision of Russian schools with it (33\%). They consider working with outdated equipment to be an important problem (29\%).

Teachers who are not overly motivated, but tend to avoid failure, have a level of motivation below average. Such teachers also use interactive whiteboards and multimedia projection systems. They find it difficult to name the programs they use. They have little knowledge of digital educational content. Teachers with below-average motivation among the advantages of ICT tools name the ability to interest students $(22 \%)$, the introduction of game methods in teaching schoolchildren, the development of student's imagination and the visualization of learning (9\%). The most popular answer about the disadvantages of using digital learning tools is the deterioration of students' vision $(8 \%)$. Most teachers find it difficult to name specific shortcomings (26\%). There are single answers: "these are expensive toys", "they take a lot of time in the lesson", etc. Among the problems that teachers with below-average motivation have to face are increased fatigue of schoolchildren (13\%), 
difficulty in managing student's attention (17\%), and insufficient material and technical support (7\%).

Above-average motivated teachers have more interesting and challenging ICT experiences, both with interactive whiteboards and multimedia systems. Among the individual answers of teachers in this group, there is experience with document cameras and electron microscopes. They work with educational content on personal computers, tablets and smartphones (this device is currently available to almost every student). Teachers have experience working with various educational content, have an idea about the programs used to develop it. Among the resources used are ready-made educational programs. Among the main advantages of digital educational products, teachers included in this group name a high degree of visibility (36\%), a higher degree of involvement of schoolchildren (14\%), facilitating the presentation of information and the formation of positive motivation in pupils (9\%). Among the single answers in this group are such as "facilitating the memorization of information", "the ability to show phenomena and objects in a safe environment", etc.

Among the disadvantages of using ICT tools in the classroom, teachers with an above-average level of motivation note the high time costs for education and training (18\%), the high cost of digital resources and technical equipment (14\%), and the likelihood of technical equipment failure $(9 \%)$. The main difficulties in the use of digital educational resources, teachers focused on the motivation of success, note the lack of separate well-equipped classrooms (64\%). Lack of time for mastering new learning tools and quality preparation for lessons is mentioned by $9 \%$ of teachers an above-average level of motivation. $14 \%$ of teachers surveyed speak of the need to further develop digital competence.

Teachers with a pronounced motivation of success use the same interactive whiteboards and multimedia projection systems, document cameras, tablets in the educational process. Digital products used in the educational process include educational platforms and websites, video tutorials, electronic diaries, digital laboratories, electronic textbooks, AR and VR programs.

Among the advantages of digital educational resources, highly motivated teachers include an increase in cognitive interest in schoolchildren (38\%), visualization of learning (32\%), the possibility of using new forms of organization of the educational process (17\%), as well as a large selection of ready-made educational content (13\%).
Success-oriented teachers, among the shortcomings of using ICT and digital educational resources, name the high cost of equipment (29\%), the potential harm to the health of students with long-term use (29\%), and the availability of cheap technology in schools (21\%). $13 \%$ of respondents are worried about the large time spent on preparation. $17 \%$ of teachers suggest difficulties in developing the imagination and fantasy of students with prolonged use of digital educational products. Among the main difficulties in the use of digital educational products in teaching, highly motivated teachers name frequently occurring technical problems with equipment (58\%), the high cost of ICT tools $(33 \%)$. $25 \%$ of respondents are worried about the potential harm to the health of students. Several success-motivated teachers note the need to improve digital competencies (17\%).

\section{DISCUSSION}

The data obtained as a result of the study allow us to speak about the relationship between the motivation of teachers and their awareness and experience in using various information and communication tools and digital educational resources.

It should be noted that success-motivated teachers have more experience in using digital educational resources and use more information and communication tools in the educational process compared to teachers who avoid failure.

A study of the experience of modern teachers shows that the majority of respondents use both multimedia projection systems and interactive whiteboards in their work. This allows us to talk about the demand for ready-made educational content, both illustrative and with the possibility of feedback.

Analyzing the answers of teachers with different levels of motivation about pedagogical tasks solved with the help of digital learning tools, a number of trends can be noticed. Thus, teachers with a higher level of motivation are characterized by a wide range of pedagogical tasks solved with the help of digital means. Failure-avoidant teachers see new learning tools most often as a new type of visual material to replace pictures in textbooks. While success-motivated teachers understand that such learning tools can stimulate the development of cognitive interest in pupil, as well as restructure the educational process.

It is obvious that teachers with a high level of motivation are not afraid to try new tools, get 
acquainted with a new type of educational content, apply it in teaching to achieve various educational results. The positive experience of the creative use of digital educational resources not only has a positive effect on their digital competencies, but also reinforces the motivation to achieve success. Systematization and critical self-assessment of their own pedagogical experience allows such teachers to identify problems in the formation of their digital competence. It is noteworthy that it is in groups with above-average level of motivation that there is a request for the further development of digital competencies.

It can be assumed that a different tactic should be used to manage the digital competencies of school teachers with low level of motivation. Teachers focused on avoiding failure require both an expansion of ideas about the possibilities of information and communication learning tools, and more practice in the use of digital educational resources in specific pedagogical situations.

Teachers who avoid failure attach great importance not only to the results of their own activities, but also to their external evaluation. Judging by the results of A.A. Rean's methodology, such teachers gravitate toward habitual activities. They avoid areas of pedagogical research where they may be incompetent. Failure can negatively affect their motivation. Therefore, in the process of developing the digital competence of teachers with the motivation to avoid failures, it is necessary to expand their understanding of the use of digital educational resources. They need not only positive practical examples, but also enough practice to feel confident in their own abilities, to independently see the improvement of their digital competencies and, as a result, the improvement of student achievement in their subject. Also, with such teachers, work should be carried out to reduce the significance of failures that are inevitable in a creative pedagogical search. Important for such teachers is the continuous methodological support of their work.

During the experiment, a tendency was revealed to focus on the use of ready-made digital educational resources and educational platforms by teachers with an above-average level of motivation. Teachers with low level of motivation are less aware of professionally designed content. They are more focused in their work on the use of programs with which you can independently develop demonstration materials for the lesson. These data may indicate that teachers with a low level of motivation do not seek to master new digital educational products, preferring their own non-professional developments to them.

The main problem in the development of teachers' digital competencies is the insufficient provision of Russian schools with ICT tools. An equally significant problem is the low digital literacy of teachers, their poor awareness of various digital educational resources, and the lack of time to learn how to work with them.

It is noteworthy that only highly motivated teachers note the negative impact of digital educational resources on the health of students among the difficulties of their work. The other groups of teachers rarely think about this problem. At the same time, the appearance of this answer suggests that in the process of developing teachers' digital competencies, it is necessary to train them in the eco-friendly use of digital educational resources by dosing work time and expediently choosing types of activities.

\section{CONCLUSION}

The results obtained allow us to draw a number of conclusions.

To successfully manage the development of digital competencies of modern teachers, it is necessary to take into account their motivation.

The strategy and tactics of developing digital competencies of teachers who avoid failure and are motivated to achieve success should be different. The first of them, as a rule, have high awareness and more experience in using digital educational resources. They are ready to solve creative methodological tasks. Therefore, teachers with a high level of motivation can act as mentors for those who are focused on avoiding failure. The latter require not only an expansion of ideas about the pedagogical possibilities of using digital content in the educational process, but also methodological and psychological support when using it. Through the use of mentoring technologies among teachers with low levels of motivation, it is possible to obtain a synergistic effect.

The results of the study can be used both in the design of higher education programs and professional training programs for teachers. The management of teachers' digital competencies should be carried out both in terms of developing their motivation, and in terms of improving digital literacy and awareness of new digital products. Within the framework of this direction, it is possible to actively involve not only more experienced 
teachers, but also representatives of the developers of digital educational resources, as well as to involve practicing teachers in the preparation of technical specifications for the development of ready-made professional digital educational products. An important area is the practical training of teachers in the work with digital learning tools. This direction can correspond to various workshops in computer classes and educational laboratories equipped with modern information and communication tools, including the latest ones that are at the testing stage and have not yet become part of mass school practice.

\section{AUTHORS' CONTRIBUTIONS}

The authors made an equal contribution to the study: collection and analysis of material; definition of goals and objectives, research methods; formulation and scientific substantiation of conclusions, registration of key research results in the form of an article.

\section{REFERENCES}

[1] K. Zhang, A.B. Aslan, "AI technologies for education: Recent research \& future directions", Computers and Education: Artificial Intelligence, 2021, p. 100025. DOI: 10.1016/j.caeai.2021.100025

[2] L.M. Brevik, G.B. Guðmundsdóttir, A. Lund, T.A. Strømme, "Transformative agency in teacher education: Fostering professional digital competence", Teaching and Teacher Education, 2019, vol. 86, p. 102875. DOI: 86.10.1016/j.tate.2019.07.005

[3] D.A. Mezentceva, E.S. Dzhavlakh, O.V. Eliseeva, A.S. Bagautdinova, "On the Question of Pedagogical Digital Competence", Higher Education in Russia, 2020, vol. 29(11), pp. 88-97. DOI: 10.31992/0869-3617-2020-29$11-88-97$

[4] W.K. Zimmer, S.D. Matthews, “A virtual coaching model of professional development to increase teachers' digital learning competencies", Teaching and Teacher Education, 2022, vol. 109, p. 103544. DOI: $10.1016 /$ j.tate.2021.103544

[5] S.M. Leahy, Ch. Holland, F. Ward, "The digital frontier: Envisioning future technologies impact on the classroom", Futures, 2019, vol. 113, p. 102422. DOI: 10.1016/j.futures.2019.04.009

[6] E.I. Chirkova, E.M. Zorina, L.V. Rezinkina, "Digital Pedagogical Cues for the Development of Creativity in High School", In book: Technology, Innovation and Creativity in Digital Society, 2022, pp 858-867. DOI: 10.1007/978-3-030-89708-6_69

[7] A.V. Ilyina, A.V. Koptelov, A.V. Mashukov, A.G. Oboskalov, "Managing the possibilities of digital competencies of teachers" [Upravleniye razvitiem tsifrovykh kompetentsiy pedagogov], Modern Pedagogical Education, 2019, vol. 4, pp. 113-119. (In Russ.).

[8] D. Tsybulsky, I. Levin, "Science teachers' worldviews in the age of the digital revolution: Structural and content analysis", Teaching and Teacher Education, 2019, vol. 86, p. 102921. DOI: $10.1016 /$ j.tate.2019.102921

[9] M. Sailer, J. Murböck, F. Fischer, "Digital learning in schools: What does it take beyond digital technology?", Teaching and Teacher Education, 2021, vol. 103, p. 103346. DOI: 10.1016/j.tate.2021.103346

[10]E.V. Yakovleva, "Digital competence of the future teacher: component structure", Koncept, 2021, vol. 4, pp. 46-57. (In Russ.). DOI: 10.24412/2304-120X-2021-11021

[11]K.Y. Wong, T. Sulaiman, A. Ibrahim, A.G. Kunchi Mohd, et al., "Secondary school teachers psychological status and competencies in e-teaching during Covid-19", Heliyon, 2021, vol. 7(3), p. 08238. DOI: 10.1016/j.heliyon.2021.e08238

[12] J. Wang, D. Tigelaar, W. Admiraal, "Rural teachers' sharing of digital educational resources: From motivation to behavior", Computers \& Education, 2021, vol. 161, p. 104055 . DOI: 10.1016/j.compedu.2020.104055

[13] E.M. Zorina, E.I. Chirkova, "Using Content and Language Integrated Learning to build students' basic skills in professional training", Csis'19 communicative strategies of information society, St. Petersburg: The Association for Computing Machinery, 2019, pp. 165-170. DOI: $10.1145 / 3373722.3373793$

[14]L. Andryukhina, N. Lomovtseva, N. Sadovnikova, "Digital didactics concepts as the basis for designing of advanced education of teachers of vocational training", Vocational Education and Labour Market, 2020, vol. 1, pp. 30-43. (In Russ.). DOI: 10.24411/23074264-2020-10103

[15]E.P. Ilyin, "Motivation and motives", Saint Petersburg: Piter, 2008, 512 p. (In Russ.) 